Available online on 15.03.2017 at http://iddtonline.info
Journal Of Drug Delivery and Therapeutics
Open access to Pharmaceutical and Medical research
noncommercial use, provided the original work is properly cited

Review Article

\title{
ANTIBIOTICS NANOSUSPENSION: A REVIEW
}

\author{
Merin Mathew*, K Krishnakumar, B Dineshkumar, Smitha K Nair \\ Dept. of Pharmaceutics, St James College of Pharmaceutical Sciences, Chalakudy, Kerala \\ St James Hospital Trust Pharmaceutical Research Centre (DSIR Recognized), Chalakudy, Kerala
}

\begin{abstract}
Nanosuspensions are colloidal dispersions and biphasic system consisting of drug particles dispersed in an aqueous vehicle in which the diameter of the suspended particle is less than $1 \mu \mathrm{m}$ in size. Many drugs including antibiotics are having poor solubility. Nanosuspensions have proven to be a better alternative over other approaches currently available for improving bioavailability of such drugs with low solubility. This review describes the methods of pharmaceutical nanosuspension of antibiotic formulations and pharmaceutical applications in drug delivery.
\end{abstract}

Keywords: Nanosuspension, Bioavailability, Solubility

Article Info

Received 19 Feb 2017; Review Completed 06 March 2017; Accepted 15 March 2017, Available online 15 March 2017

Cite this article as:

Mathew M, Krishnakumar K, Dineshkumar B, Nair SK, Antibiotics Nanosuspension: A Review, Journal of Drug Delivery and

\begin{tabular}{ll} 
Therapeutics. 2017; 7(2):128-131 $\quad$ DOI: http://dx.doi.org/10.22270/jddt.v7i2.1406 \\
\hline
\end{tabular}

*Address for Correspondence

Merin Mathew, Dept. of Pharmaceutics, St James College of Pharmaceutical Sciences, Chalakudy, Kerala Email: stjamespharmacyproject@gmail.com

\section{INTRODUCTION}

Nanotechnology is likely to make a big change in our lives, in general, and health scenario, in particular. It is one of the most important research and development area in today's era. Nanotechnology is an applicable aspect of a broader area of nanoscience which is one of the upcoming and highly challenging as well as rewarding key research area in the modern scientific set up ${ }^{1}$. It is the science of small particle having unique properties, which change on altering the size of the particle ${ }^{2}$. Nanosuspensions are colloidal dispersions and biphasic system consisting of drug particles dispersed in an aqueous vehicle in which the diameter of the suspended particle is less than $1 \mu \mathrm{m}$ in size. Reduction of drug particles to nanometer range leads to an enhanced dissolution rate due to increased surface area and saturation solubility ${ }^{3}$. A nanosuspension not only solves the problem of poor solubility and bioavailability but also alters the pharmacokinetics of drug and improves the drug safety and efficacy. Nanosuspension has been reported to enhance absorption and bioavailability.

\section{IMPORTANCE OF ANTIBIOTICS AS NANOSUSPENSION}

Antibiotics also called anti-bacterial are a type of antimicrobial drug used in the treatment and prevention of bacterial infections. They may either kill or inhibit the growth of bacteria. Many antibiotics such as Ciprofloxacin, Sulfadiazine, belong to BCS class II/IV, having poor solubility and dissolution rate. Nanosizing of such drugs leads to a drastic increase in their oral absorption and consequently bioavailability. The increase in bioavailability is due to increased surface area of the particles, increased saturation solubility and increase in dissolution velocity. The drug dose reduction is possible with enhancement in bioavailability making therapy cost effective and in preventing toxicity ${ }^{4}$. Formation of nanoparticles could provide some benefits such as increased saturation solubility and drug dissolution rate, improved bioavailability and dose proportionality, and inter-subject variability in comparison with the coarse or micronized drug powder. ${ }^{5}$ 


\section{METHODS OF PREPARATION ${ }^{6-13}$}

Preparation of nanosuspension is reported to be simpler and cost effective. It is particularly for poorly soluble drugs and to yield a physically more stable product. For manufacturing nanosuspensions, there are two methods, "Top-down process technology" and "Bottom-up process technology".

The top -down process includes:-

* High pressure homogenization

* Media milling (Nanocrystals).

Bottom-up process includes:-

* Solvent- Antisolvent method

* Super critical fluid process

* Emulsification Solvent evaporation technique

* Lipid emulsion/Micro-emulsion template.

The principle techniques used in recent years for preparing nanosuspensions are:

\section{High pressure homogenization:}

It is most widely used method for preparing nanosuspensions of many poorly aqueous soluble drugs . It involves three steps. First, the drug powders are dispersed in stabilizer solution to form pre-suspension, and then the pre-suspension is homogenized in high pressure homogenizer at a low pressure for pre-milling, and finally homogenized at high pressure for 10 to 25 cycles until the nanosuspensions of desired size are formed.

\section{Milling techniques:}

\section{a) Media Milling:}

This method was first developed and reported by Liversidge (1992). The nanosuspensions by this method are prepared by high shear media mill. The milling chamber is charged with the milling media, water, drug and stabilizer and rotated at a very high shear rate under controlled temperature for atleast 2-7 days. The milling medium is composed of glass, Zirconium oxide or highly cross linked polystyrene resin. The high energy shear forces are formed as a result of impaction of milling media with the drug which results in breaking of drug microparticles to nanosized particles.

\section{b) Dry-Co-grinding:}

Recently many nanosuspensions are prepared by dry milling technique. Dry- co-grinding can be carried out easily and economically and can be conducted without organic solvents. Physicochemical properties and dissolution of poorly water soluble drugs are improved by Co-grinding because of the improvement in the surface polarity and transformation from a crystalline to an amorphous drug.

\section{Emulsification-solvent evaporation technique}

This technique involves preparing a solution of drug followed by its emulsification in another liquid that is a nonsolvent for the drug. Evaporation of the solvent leads to precipitation of the drug. Crystal growth and particle aggregation can be controlled by creating high shear forces using a high-speed stirrer.

\section{Precipitation method}

Within the last decade, precipitation has been applied to prepare submicron particles, especially for the poorly soluble drugs. The drug is first dissolved in a solvent, then this solution is mixed with a miscible anti-solvent in the presence of surfactants. Rapid addition of a drug solution to the anti-solvent leads to sudden super saturation of drug and formation of ultrafine crystalline or amorphous drug solids.

\section{Supercritical fluid process}

The particle size reduction was achieved more by the solubilisation and nanosizing technologies through the super critical fluid process. Super critical fluids (SCF) are non-condensable dense fluids whose temperature and pressure are greater than its critical temperature (Tc) and critical pressure (Tp). This process allows the micronization of drug particles to a submicron level. Recent advances in SCF process are to create nanoparticulate suspension of particle size of 5 to $2000 \mathrm{~nm}$ in diameter.

\section{Melt emulsification method}

In this method drug is dispersed in the aqueous solution of stabilizer and heated above the melting point of the drug and homogenized to give an emulsion. During this process, the sample holder will be enwrapped with a heating tape fitted with temperature controller and the temperature of emulsion will be maintained above the melting point of the drug. The emulsion is then cooled down either slowly to room temperature or in an ice-bath.

\section{Lipid emulsion/microemulsion template:}

This method is mostly applicable for drugs that are soluble in either volatile organic solvents or partially water miscible solvents. In this method, the drug is dissolved in suitable organic solvent and then emulsified in an aqueous phase using suitable surfactants. Then the organic solvent is slowly evaporated under reduced pressure to form drug particles precipitating in the aqueous phase forming the aqueous suspension of the drug in the required particle size. Then the suspension formed can be suitably diluted to get nanosuspensions. Moreover, microemulsions as templates can produce nanosuspensions. Microemulsions are thermodynamiccally stable and isotropically clear dispersions of two immiscible liquids such as oil and water stabilized by an interfacial film of surfactant and co-surfactant. The drug can be either loaded into the internal phase or the preformed microemulsion can be saturated with the drug by intimate mixing. Suitable dilution of the microemulsion yields the drug nanosuspension.

\section{Solvent evaporation:}

In the solvent evaporation method, the solutions of polymer are prepared in volatile solvents and emulsions. The emulsion is converted into a nanoparticle suspension on evaporation of the solvent for the polymer, which is allowed to diffuse through the continuous phase of the emulsion. In the conventional methods, two main strategies are being used for the formation of emulsions, the preparation of single- 
emulsions, e.g., oil-in-water $(\mathrm{o} / \mathrm{w})$ or double-emulsions, e.g., (water-in-oil)-in-water, (w/o)/w. These methods require high-speed homogenization or ultrasonication, followed by evaporation of the solvent, either by continuous magnetic stirring at room temperature or under reduced pressure. By ultracentrifugation the solidified nanoparticles are collected which is washed with distilled water to remove the additives like surfactants, and then it is lyophilized. The particle size is influenced by the concentration of polymer, stabilizer and the speed of homogenizer.

Table 1: Summary of the nanosuspension formation technologies [14,15]

\begin{tabular}{|c|c|c|c|}
\hline Technology & Advantages & Disadvantages & Drugs \\
\hline Precipitation & $\begin{array}{l}\text { Equipment cost is low } \\
\text { Ease of scale up }\end{array}$ & $\begin{array}{l}\text { Drug has to be soluble in atleast one } \\
\text { solvent }\end{array}$ & $\begin{array}{l}\text { Carbamazepine } e^{16} \\
\text { Cyclosporine }^{17}\end{array}$ \\
\hline $\begin{array}{l}\text { High Pressure } \\
\text { Homogenisation }\end{array}$ & $\begin{array}{l}\text { Applicable to most drugs } \\
\text { Simple technique with aseptic } \\
\text { production possible } \\
\text { Risk of product } \\
\text { Contamination is low }\end{array}$ & $\begin{array}{l}\text { Prerequisite for drug to be in micronized } \\
\text { state and suspension formation before } \\
\text { homogenization }\end{array}$ & $\begin{array}{l}\text { Amphotericin B } \\
\text { Azithromycin }^{19} \\
\text { Budesonide }^{20} \\
\text { Clofazamine }^{21} \\
\text { Fenofibrate }^{22} \\
\text { Ibuprofen }^{23} \\
\text { Itraconazole }^{24}\end{array}$ \\
\hline $\begin{array}{l}\text { Emulsion / } \\
\text { Microemulsion }\end{array}$ & $\begin{array}{l}\text { High drug solubilisation } \\
\text { Long shelf life }\end{array}$ & $\begin{array}{l}\text { Use of hazardous solvent and high } \\
\text { amount of surfactant and stabilizers }\end{array}$ & $\begin{array}{l}\text { Mutotane }^{25} \\
\text { Griseofulvin }\end{array}$ \\
\hline Media Milling & $\begin{array}{l}\text { Ease of scale up } \\
\text { Batch to batch variation is little } \\
\text { High flexibility in handling of large } \\
\text { quantities of drugs }\end{array}$ & $\begin{array}{l}\text { Generation of residue of milling media } \\
\text { It requires milling process from hrs to } \\
\text { days. }\end{array}$ & $\begin{array}{l}\text { Cilostazol }^{27} \\
\text { Danazol }^{28} \\
\text { Naproxen }^{29}\end{array}$ \\
\hline Dry Co-Grinding & $\begin{array}{l}\text { Easy process } \\
\text { No organic solvent is needed } \\
\text { It requires short grinding time }\end{array}$ & $\begin{array}{l}\text { There is generation of residue of milling } \\
\text { media }\end{array}$ & $\begin{array}{l}\text { Clarithromycin }{ }^{30} \\
\text { Glibenclamide }^{31}\end{array}$ \\
\hline
\end{tabular}

\section{APPLICATIONS $32-34$}

\section{- Oral administration}

Nanosizing of drugs leads to an increased oral absorption and subsequent bioavailability. Improved bioavailability is due to the adhesiveness of drug nanoparticles to the mucosa and the increased saturation solubility leading to an increased concentration gradient between gastrointestinal tract lumen and blood. Aqueous nanosuspensions can be used directly in a liquid dosage form and a dry dosage form such as tablet or hard gelatin capsule with pellets. Granulates can also be produced by spray drying of nanosuspensions.

\section{- Ophthalmic drug delivery}

Nanosuspensions have been providing to be vital for drugs that exhibit poor solubility in lachrymal fluids. Suspensions offer advantages such as prolonged residence time, which is desirable for most ocular diseases for effective treatment and avoidance of high tonicity created by water soluble drugs. Their actual performance depends on the intrinsic solubility of the drug in lachrymal fluids. Thus the intrinsic dissolution rate of the drug in lachrymal fluids governs its release and ocular bioavailability.

\section{- Intravenous administration}

Parenteral route of administration provides a quick onset of action, rapid targeting and reduced dosage of the drug. It is the preferred route for drugs undergoing first-pass metabolism and those that are not absorbed in the GIT or that get degraded in the GIT. One of the important applications of nanosuspension technology is the formulation of intravenously administered products. IV administration results in several advantages, such as administration of poorly soluble drugs without using a higher concentration of toxic cosolvents, improving the therapeutic effect of the drug available as conventional oral formulations and targeting the drug to macrophages and the pathogenic microorganisms residing in the macrophages.

\section{- $\quad$ Targeted drug delivery}

Nanosuspensions can also be used for targeted delivery as their surface properties and in vivo behaviour can easily be altered by changing either the stabilizer or the milieu. Their versatility, ease of scale up and commercial product has helped in developing commercial viable nanosuspensions for targeted delivery.

\section{- Pulmonary administration}

Aqueous nanosuspensions can be nebulized using mechanical or ultrasonic nebulizers for delivery of the drug into lungs. Because of their small size, it is likely that in each aerosol droplet at least one drug particle is contained, leading to a more uniform distribution of the drug in lungs. They also increase adhesiveness and thus cause a prolonged residence time. Budenoside drug nanoparticles were successfully nebulized using an ultrasonic nebulizer.

- Mucoadhesion of the nanoparticles

Nanoparticles orally administered in the form of a suspension diffuse into the liquid media and rapidly encounter the mucosal surface. The particles are immobilized at the intestinal surface by an adhesion mechanism referred to as "bioadhesion". Then, the concentrated suspension acts as a reservoir of particles and an adsorption process takes place rapidly. The direct contact of the particles with the intestinal cells through a bioadhesive phase is the first step before particle absorption. The adhesiveness of the nanosuspensions not 
only helps to improve bioavailability but also improves targeting of the parasites persisting in the GIT.

\section{CONCLUSION}

The nanosuspension technology have been successfully proved to be useful for overcoming problem associated with poorly soluble drugs or lipophilic drugs insoluble in both organic and aqueous media. Large scale production of nanosuspension can be employed by media milling and

\section{REFERENCE}

1. Mitesh Patel, Arpit Shah, Dr. N.M. Patel, Dr. M.R. Patel, Dr. K.R. Patel. Nanosuspension: A novel approch for drug delivery system. Journal of Pharmaceutical Science \& Bioscientific Research. 2011; 1(1): $1-10$.

2. Dubey R. Impact of nanosuspension technology on drug discovery and development. Drug Delivery Technology. 2006; 6: 65-7.

3. Kocbek P, Baumgartner S, Krist J. Preparation and evaluation of nanosuspensions for enhancing the dissolution of poorly soluble drugs. International Journal of Pharmaceutics. 2006; 312:179-86.

4. Pawar RN, Chavan SN and Menon MD. Development, characterization and evaluation of tinidazole nanosuspension for treatment of amoebiasis. Journal of Nanomedicine \& Nanotechnology. 2016; 7(6):1-4

5. Elham Ghasemian, Behnaz Rezaeian, Samaneh Alaei, Alireza Vatanara , Vahid Ramezani. Optimization of cefixime nanosuspension to improve drug dissolution.Journal of Pharmaceutical Sciences. 2015; 21(1):136-44.

6. Roya Yadollahi, Krasimir Vasilev, Spomenka Simovic. Nanosuspension technologies for delivery of poorly soluble drugs-A review. Journal of Nanomaterials. 2015 (2015):1-13.

7. Kamble VA, Jagdale DM, Kadam VJ. Nanosuspension a nove drug delivery system. International Journal Of Pharma And Bio Sciences, 2010;1(4):348-52.

8. Geetha G, Poojitha U, Khan UAA. Various techniques for preparation of nanosuspension- A Review . International Journal of Pharma Research \& Review.2014; 3(9):30-7.

9. Venkatesha T, Reddy AK, Maheswaria JU, Dalithb MD, Kuma CKA. Nanosuspensions: ideal approach for the drug delivery of poorly watersoluble drugs. Scholars Research Library Der Pharmacia Lettre, 2011, 3(2):203-13.

10. Xiaohui $\mathrm{Pu}$, Jin Sun, Mo $\mathrm{Li}$ and Zhonggui He. Formulation of nanosuspensions as a new approach for the delivery of poorly soluble drugs. Current Nanoscience, 2009; 5: 417-27.

11. Vishal R. Patel and Y. K. Agrawal. Nanosuspension: An approach to enhance solubility of drugs. Journal of Advanced Pharmaceutica Technology \& Research. 2011; 2(2): 81-7.

12. Miryala V, Kurakula M, Self-nano emulsifying drug delivery system (SNEDDS) for oral delivery of atorvastatin- formulation and bioavailability studies, Journal of Drug Delivery \& Therapeutics; 2013, 3(3):131-142

13. Shah DP, Patel B, Shah C, Nanosuspension technology: An innovative slant for drug delivery system and permeability enhance for poorly water soluble drugs, Journal of Drug Delivery \& Therapeutics. 2015; 5(1):10-23

14. X Chen, TJ Yong, M Sarkari, RO Williams III and KP Johnston Preparation of cyclosporine A nanoparticles by evaporative precipitation into aqueous solution. International Journal of Pharmaceutics. 2002; 242(1-2): 3-14.

15. Zili Z, Sfar S, Fessi H. Preparation and characterization of poly- $\varepsilon$ carprolactone nanoparticles containing griseofulvin. International Journal of Pharmaceutics. 2005; 294(1-2):261-7.

16. Müller RH, Jacobs C, Kayser O. Nanosuspensions as particulate drug formulations in therapy rationale for development and what we can expect for the future. Advanced Drug Delivery Reviews. 2001; 47(1):3-19.

17. Zhang D, Tan T, GAO L, Zhao W, Wang P. Preparation of azithromycin nanosuspensions by high pressure homogenization and its physicochemical characteristics studies. Drug Development \& Industrial Pharmacy. 2007; 33(5): 569-75.

18. Müller RH, Jacobs C. Production and characterization of a budesonide nanosuspension for pulmonary administration. Pharmaceutical Research. 2002; 19(2): 189-94. high pressure homogenization technique. The recent advancement in the work being done related to nanosuspension shows that many formulations are being developed on a laboratory scale which have a potentially important clinical significant to treat diseases. Thus, nanosuspension technology is able enough to bring enormous immediate benefits and will revolutionize the research and practice of medicine in the field of pharmacy.

19. Müller RH, Jacobs C and O Kayser. Nanosuspensions as particulate drug formulations in therapy rationale for development and what we can expect for the future. Advanced Drug Delivery Reviews. 2001; 47(1): 3-19.

20. Hanafy A, Spahn-Langguth H, Vergnault G, Grenier P, Grozdanis MT, Lenhardt T. Pharmacokinetic evaluation of oral fenofibrate nanosuspension and SLN in comparison to conventional suspensions of micronized drug. Advanced Drug Delivery Reviews. 2007; 59(6):419-26.

21. Kocbek P, Baumgartner S, Kristl J. Preparation and evaluation of nanosuspensions for enhancing the dissolution of poorly soluble drug. International Journal of Pharmaceutics. 2006; 312(1-2): 179-86.

22. Rainbow B, Kipp, P Papadopoulos, J Wong, J Glosson, J Gass, C-S Sun, T Wielgos, R White, C Cook, K Barker and $\mathrm{K}$ Wood. Itraconazole IV nanosuspension enhances efficacy through altered pharmacokinetic in the rat. International Journal of Pharmaceutics. 2007; 339(1-2): 251-60

23. Trotta M, Gallarete ME, Pattarino F, Morel S. Emulsions containing partially water-miscible solvents for the preparation of dry nanosuspensions. Journal of Controlled Release. 2001; 76(1-2):11928.

24. Trotta M, Gallarete ME, Pattarino F, Morel S. Preparation of griseofulvin nanoparticles from water-dilutable microemulsions. International Journal of Pharmaceutics. 2003; 254(2):235-42.

25. Jinno J-I, Kamada N, Miyake M, Yamada K, Mukai T, Odomi M ET AL. Effect of particle size reduction on dissolution and oral absorption of a poorly water-soluble drug, cilostazol, in beagle dogs. Journal of Controlled Release.2006; 111(1-2): 56-64.

26. E Merisko-Liversidge, GG Liversidge and ER Cooper. Nanosizing: a formulation approach for poorly-water-soluble compounds. European Journal of Pharmaceutical Sciences. 2003; 18(2):113-20.

27. Liversidge GG and Conzentino P. Drug particle size reduction for decreasing gastric irritancy and enhancing absorption of naproxen in rats. International Journal of Pharmaceutics. 1995; 125:309-13.

28. Yonemochi E, Kitahara S, SMaeda, Yamamura S, Oguchi T and Yamamoto K. Physicochemical properties of amorphous clarithromycin obtained by grinding and spray drying. European Journal of Pharmaceutical Sciences. 1999; 7(4):331-8.

29. Itoh K, Pongpeerapat A, Tozuka Y, Oguchi T and KYamamoto. Nanoparticle Formation Of Poorly Water Soluble Drugs From Ternary Ground Mixtures With PVP And SDS. Chemical \& Pharmaceutical Bulletin. 2003; 51:171-4.

30. T Watanabe, I Ohno, $\mathrm{N}$ Wakiyama, A Kusai and M Senna. Stabilization of amorphous indomethacin by co-grinding in a ternary mixture. International Journal of Pharmaceutics.2002; 241(1): 10311.

31. Khan AD, Singh L, Various techniques of bioavailability enhancement: a review, Journal of Drug Delivery \& Therapeutics. 2016; 6(3):34-41

32. Das S. Nanosuspension: An assuring novel drug delivery system. International Journal of Pharmaceutical Sciences Review \& Research. 2013; 20(1):228-31.

33. Muller RH, Jacobs C. Production and characterization of budenoside nanosuspension for pulmonary administration. Journal of Pharmaceutical Research. 2002; 19(2):189-94.

34. Ponchel G, Montisci MJ, Dembri A, Durrer C, Duchкne. D. Mucoadhesion of colloidal particulate systems in the gastrointestinal tract. European Journal of Pharmaceutics \& Biopharmaceutics.1997; 44(1): $25-31$ 